Quebec Cooperative Study of

Friedreich's Ataxia

\title{
Design of the Investigation
}

\author{
A. BARBEAU
}

SUMMARY: The general outline of the complete prospective study of 50 cases of spino-cerebellar degeneration is given. The general protocol followed, the criteria for inclusion and the mode of analysis are described. The aim of this study was to establish a base of clinical, physiological and biochemical facts upon which a logical and systematic approach to pathogenesis and treatment of Friedreich's ataxia could be attempted.

RESUMÉ: Nous présentons une description générale de l'étude prospective complète de 50 patients souffrant de dégénérescence spino-cérébelleuse. Le protocole adopté, les critères d'inclusion et le mode d'analyse sont décrits. Le but principal de la présente investigation était d'établir une base solide de faits cliniques, physiologiques et biochimiques, base sur laquelle il serait éventuellement possible de planifier une approche logique et systématique à la pathogénèse et au traitement de l'ataxie de Friedreich.

From the Department of Neurobiology. Clinical Research Institute of Montreal.

Reprints requests for the complete supplement on Friedreich's ataxia to: Dr. André Barbeau, Clinical Research Institute of Montreal, 110 Pine Avenue West, Montreal, Quebec, Canada H2W IR7.
Friedreich's ataxia has resisted precise clinical and biochemical definition, despite the detailed descriptions by Friedreich between 1861 and 1877 (Friedreich, 1861, 1863a, b, c; 1875a, b; 1876; 1877) and despite the subsequent attempts by neurologists and neuropathologists (Greenfield, 1954; Tyrer, 1975). Confusion persists regarding the place of this spinocerebellar degeneration within the complex nosography of hereditary ataxias (Figure 1). The mode of inheritance is open to question even if the majority of cases appear to be acquired in an autosomal recessive fashion. Phenotypically similar entities (such as cerebellar ataxias, familial spastic paralysis, Roussy-Levy syndrome, Charcot-Marie-Tooth's disease) can appear within the same large family tree (Schut, 1950, 1951). Although certain findings are common to most cases, the pathological spectrum uncovered is wide and intermediate examples are found between almost all subgroups of hereditary ataxias, and with apparently unrelated neurological entities (Greenfield, 1954). A recent review of biochemical findings (Lubozynski et al, 1975) indicates confusion and uncertainty. This was the background and situation when the present multicenter cooperative study was initiated in the spring of 1974 . It is fitting at this stage to recount the steps which led to the conception and implementation of the present approach and to explain the general procedures adopted and the difficulties encountered.

The story of Claude St-Jean (Figure 2), of his illness, his struggles, his courage and determination, has been told many times on television and in the lay press (see Reader's Digest, Canada, January 1976), but it cannot be emphasized enough how he single-handedly created L'Association Canadienne de l'Ataxie de Friedreich, how he coaxed, cajoled and coerced some 60 Quebec clinicians and scientists, not only to join in the fight against Friedreich's ataxia, but to do so benevolently and with growing enthusiasm. He lights the fire and at the same time is the flame and fuel of the whole project. He raises the necessary funds, orchestrates the public relation aspect and still finds time to visit each year over 100 patients, members of the Association, while convincing them that the time they spend with the scientists is not only important, but personally rewarding. The present report of progress by these same scientists is the result of the foresight and tenacity of one man. To this man, Claude St-Jean, this report is dedicated, in the hope that the light now seen at the end of the tunnel, will help in mastering his own illness.

When the Association was formed in the fall of 1973, the first decision of the Scientific Board was to attempt a multicenter, multidisciplinary approach to the problem, starting from zero and, in a prospective fashion, reassessing all the "facts", opinions and theories about that illness, including such basic tenets as the clinical-spectrum and the mode of inheritance. In many ways the Province of Quebec is an ideal place to locate such a study. Of the 7 million inhabitants, 6 million originate from a small stock (less than 70,000 ) of French immigrants who landed in the New World before 1760. Consanguinity rate was extremely high during the first 6-8 generations with a number of geographic and genetic isolates. Church records for this whole period (from 
SPINO - CEREBELLAR DEGENERATIONS

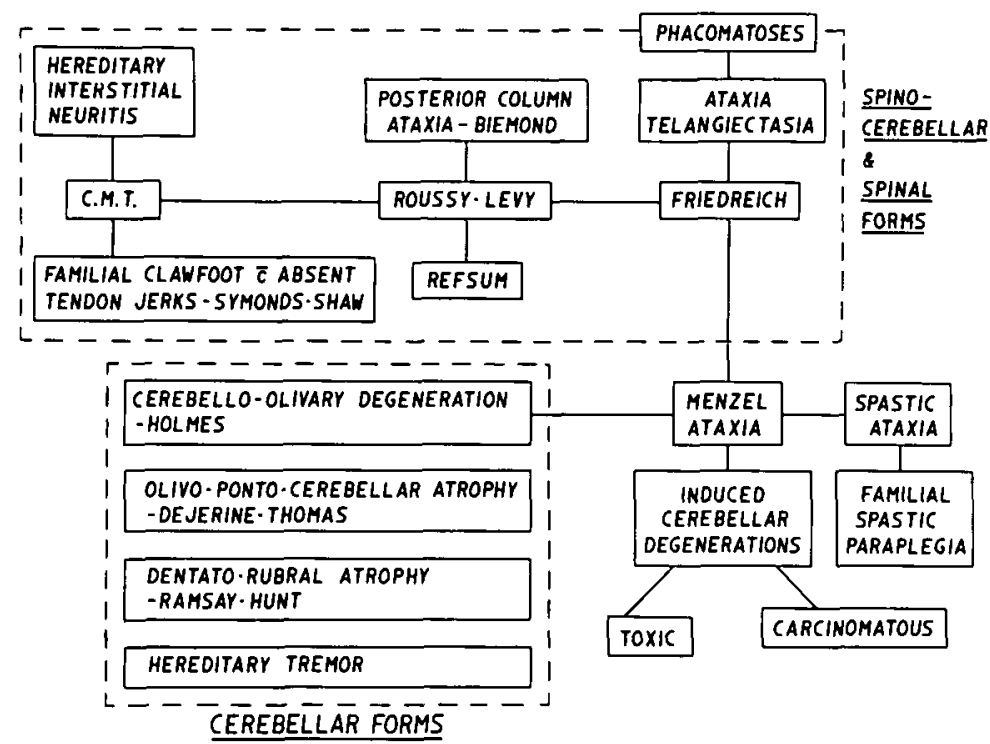

Figure 1-A schematic classification of the various clinical entities where ataxia is a main feature.

1608 to the present day) are almost intact, and have been collated and classified. Moreover, there are 4 medical schools in the Province (Université de Montréal and McGill University in Montreal, Université de Sherbrooke in Sherbrooke, and Université Laval in Quebec City) with neurologists in constant contact with each other through society and association meetings. For most of the last decade every resident of the Province has benefited from state paid hospitalization insurance, and more recently from similar health care insurance. This, with the knowledge and cooperation of the federal and provincial authorities, permitted the hospitalization of many patients for long periods in metabolic units, at no direct cost to the patients or the Association Canadienne de l'Ataxie de Friedreich. Without this very generous indirect contribution from the governments, this project could not have taken place.

The multicenter cooperative study, which is continuing, has evolved in four different phases: First, the Scientific Board carried out a detailed search and review of the literature on Friedreich's ataxia since 1861. More than 1,000 articles were photocopied, read, abstracted and cross-indexed. From these, lists of clinical, paraclinical, physiologi- cal and biochemical findings were made which directly or secondarily were thought to be linked to Friedreich's ataxia. It must be stated that many times an item had been studied on only a few patients, and only by one author (for example: 5 patients investigated for urinary amino acids, 3 for blood ceruloplasmin levels, etc.). This item nevertheless, was placed on our lists for eventual inclusion into the protocol. It must also be stated that almost all studies consulted, even when numbers of patients were large, were of the retrospective type. The Association intends to publish, in the near future, an updated, indexed bibliography on Friedreich's ataxia based on this literature search. Meanwhile, however, the best complete references are to be found in the reviews by Greenfield (1954) and Tyrer (1975).

The second phase, consisted of the preparation of the protocol to be followed for each patient admitted to the prospective study. Taking into account the facilities and funds at our disposal, and the pool of patients available it was decided to enter 50 cases of Friedreich's ataxia into the detailed study and to plan the protocol so that all investigations could be carried out, in a hospital metabolic unit, within 3 to 4 weeks for each patient. The first difficulty encountered was to define Friedreich's ataxia. It was decided to accept into the study any patient who had received (in the past) the clinical diagnosis of Friedreich's ataxia from at least two certified neurologists. The planning board accepted the fact that this would lead to some heterogeneity of the group, but this was felt to be an advantage. If a specific biochemical abnormality were found, a "blind" control group would have thus been provided in the course of the complete study. From the literature search and the indexed lists of "findings" related to Friedreich's ataxia, broad areas of investigation were defined. It was decided to include in the protocol every determination which had been claimed to be abnormal in Friedreich's ataxia, even if based on a few cases and not confirmed.

During the preparation of the protocol, teams of specialist consultants were formed to help us in selecting, for each principal metabolic pathway, a series of screening tests that could predict the integrity or derangement of that pathway, even if unable to pin-point the specific enzyme defect. That task would be reserved for a subsequent phase of the investigation. For example, glucose metabolism was screened by the following tests: oral and intravenous glucose tolerance tests, insulin determinations fasting and after glucose, blood pyruvate and lactate responses to oral or intravenous glucose, liver and renal function tests, glycosuria, lactic dehydrogenase $(\mathrm{LDH})$ and other enzymes. All major metabolic pathways were thus covered. Unfortunately, because of financial considerations, we had to abandon plans for a complete screening of steroid and hormonal metabolism. In this way, a total of 17 clinical, 9 physiological and 32 biochemical items were included into the final protocol to be administered to each patient. Each clinical team was free to select and organize the actual order of the tests according to local conditions and facilities. However, a special "standardization commit- 


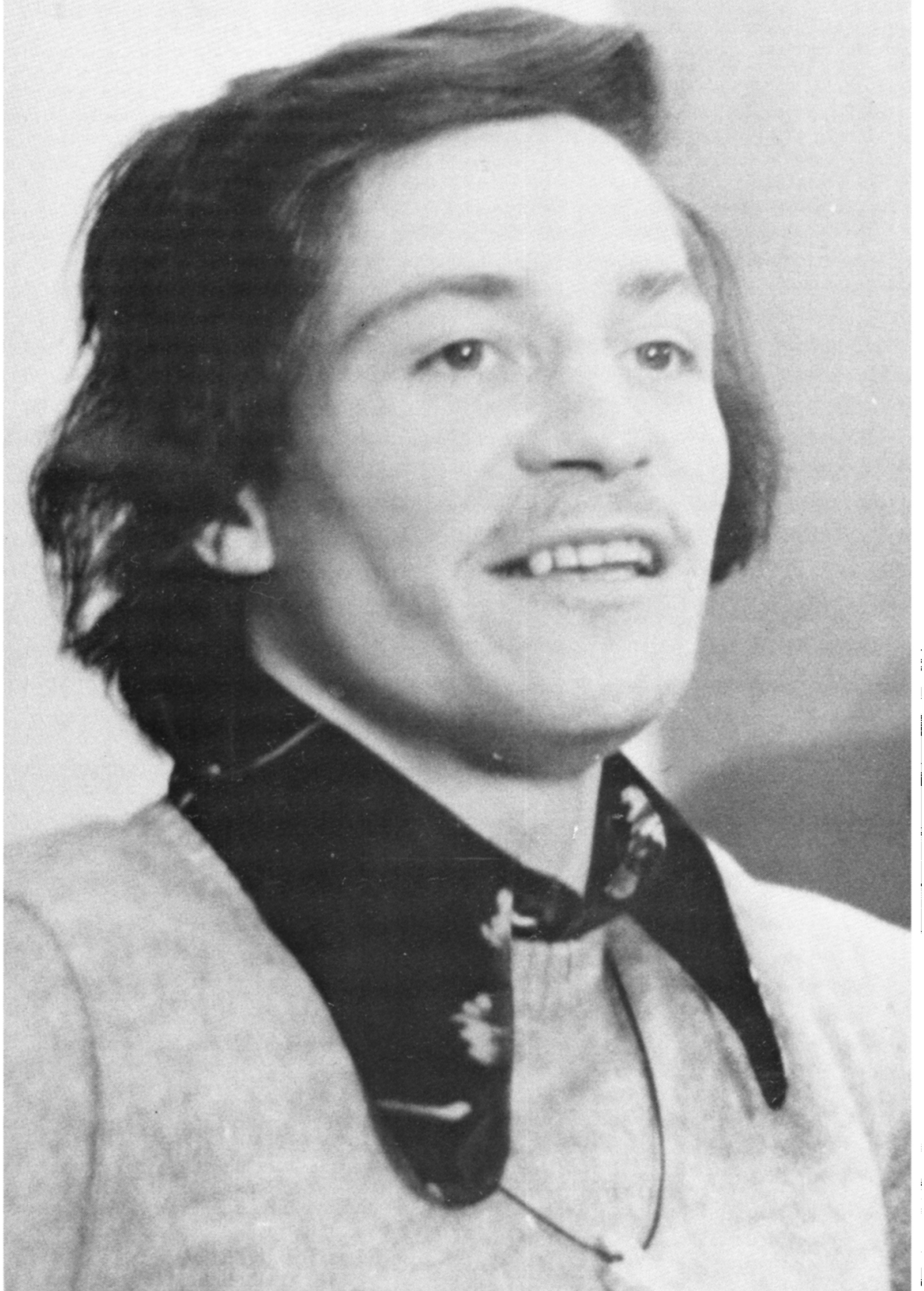

Figure 2-Claude St-Jean, founder and president, L'Association Canadienne de l'Ataxie de Friedreich.

tee" was formed to verify and compare the methodologies employed in each center, since it was not feasible, except in specific instances, to centralize all determinations. Despite these necessary precautions, it was still impossible in a few cases to reconcile the determinations carried out in some centers. This will explain some omissions in the tables: almost all tests were carried out in all patients, but unfortunately not all results could be accepted by the standardization committee. On a few occasions, in the course of the study, it was necessary to add a few items to the protocol in the light of findings by the group or others. The most conspicuous of these additions concerns pyruvate metabolism. As seen above, an investigation of pyruvate and lactate response to glucose had been included in the protocol, as part of the screening tests for glucose metabolism. Within the first few months of the study, abnormal findings were recorded, and reported (Barbeau, 1975). These changes were independently found and investigated in more detail by Kark and his co-workers, unknown to us. When their paper was published (Kark et al, 1975), some important modifications were made to the protocol to include detailed studies of pyruvate metabolism and of the enzymes involved. Unfortunately, these latter studies could not be carried out in all the involved centers, and therefore do not include all 50 patients.

The third phase of the study was the actual testing of the 50 patients. As a preliminary step all 60 participating clinicians and scientists were gathered for a 3 day workshop in October 1974 where the protocol was presented, discussed and the mechanics of the experiment finished. It was decided that the clinical groups at each medical school involved would hospitalize approximately 15 patients each. Subsequent events made this impossible. Eventually all 50 subjects were studied at 3 of the cooperating centers: 22 at the Hotel-Dieu Hospital in Montreal, 8 at the Ste-Justine Hospital for Children in Montreal and 20 at the Centre Hospitalier Universitaire in Sherbrooke. Some of these patients had previously been hospitalized elsewhere in the province. Their complete records were made available to us (including original $X$-Ray films and recordings) by their physicians and other hospitals. The 50 patients were studied between October 1974 and August 1975. This was only possible through the untiring efforts of various members of L'Association Canadienne de l'Ataxie de Friedreich who volunteered for this study or helped in getting other candidates from faraway places to the three centers and provided social visits during their stay in hospital.

The fourth phase of the present study was the arduous task of collating the results. This amounted to thousands of reports, figures or recordings. Once the results had been compiled, and some statistics de- 
rived, a series of weekend workshops were organized to help analyze and interpret the findings. In each of these workshops the clinicians and biochemists were helped by expert consultants who provided critical balance to the discussions. $X$-Ray findings, electrophysiological recordings (EEG, EMG), biochemical results and clinical observations were individually reviewed. As will be clear from the papers in this report, agreement was not always reached, and many points are still unclear. One of the workshops, concerned with clinical results, involved a panel of 15 neurologists who reviewed the history and physical findings of each individual patient, with the help of movie films taken following a standard protocol. In this way, and with the added experience of this year of intensive study of ataxia cases (many more cases were screened during that time by the participating neurologists, even if not included in the first study), the panel was able to reach a unanimous concensus on the diagnosis of "typical Friedreich's ataxia" in 36 of the 50 cases studied (Group I). The remaining 14 patients did not draw unanimity from the panel and will be referred to as Group II or atypical cases. For some of these patients, the diagnosis of Roussy-Levy syndrome or even of Charcot-MarieTooth disease was proposed, but never unanimously. Throughout the following papers these two groups will always be analyzed separately. However, it is recognized that this separation, although unanimously accomplished, is only based on clinical facts and may permit a certain number of overlaps and misclassifications. Until a biochemical defect has been identified, such a classification is about the best that can be accomplished. Already biochemical sub-groups have been tentatively identified and belie the apparent homogeneity of the clinical groupings. During the course of the study one patient died and was autopsied. The results of these investigations, as well as other findings gathered from biopsies, will be reported in a later phase of our cooperative study.

Once the group analysis of the results had been accomplished, the task of writing the findings for publication was distributed amongst the various participants. The present publication is the combined result of all their efforts and that of many unamed others. It is not intended as a definitive or final presentation, but as a situation report. From such an extended, and prospective study of a large (50) number of spinocerebellar degeneration cases, we believe we can establish a base of verified physiological and biochemical facts from which to plan further investigations of Friedreich's ataxia. Such facts were previously difficult, if not impossible, to obtain from the literature in such a wide spectrum in the same patients. This is our main justification for publishing together so many negative or inconclusive results along with a few promising observations. Further results of this continuing cooperative study will be reported later.

\section{ACKNOWLEDGMENTS}

The multidisciplinary studies carried out in the various centers involved in this survey were supported almost entirely by public funds raised expressly for this by the Association Canadienne de l'Ataxie de Friedreich. Certain more specific studies in individual centers also received financial help from a variety of sources: the Medical Research Council of Canada, the Jeanne Mance Foundation of the Hotel-Dieu Hospital, the W. Garfield Weston Foundation. The Ministries of Health (federal and provincial cost sharing formula) gave considerable indirect support to this research by underwriting the extremely expensive item of the patients hospitalization in metabolic units.

\section{REFERENCES}

BARBEAU, A. (1975). Prelininary studies on pyruvate metabolism in Friedreich's ataxia. Trans. Amer. Neurol. Assoc., 100, 164-165.

FRIEDREICH, N. (1861). Ueber degenerative atrophie der spinalen hinterstränge. Congress sitzungsbericht der Deutschen Aerzte und Naturforscher, Speier.

FRIEDREICH, N. (1863a). Ueber degenerative atrophie des spinalen hinterstränge. Virchows Arch. Path. Anat. (Berlin, 26, 391-419.

FRIEDREICH, N. (1863b). Ueber degenerative atrophie des spinalen hinterstränge. Virchows Arch. Path. Anat. (Berlin), 26, 433-459.

FRIEDREICH, N. (1863c). Ueber degenerative atrophie des spinalen hinterstränge. Virchows Arch. Path. Anat. (Berlin), 27, 1-26.

FRIEDREICH, N. (1875a). Ueber hereditäre ataxie. Allgemeine Zeitschrift f. Psychiatr., $32,539$.

FRIEDREICH, N. (1875b). Ueber statische ataxie und ataktischen nystagmus. Arch. f. Psychiat., 7, 235.

FRIEDREICH, N. (1876). Ueber ataxie mit besonderer berücksichtigung der hereditären formen. Virchows Arch. Path. Anat., 68, 145-245.

FRIEDREICH, N. (1877). Ueber ataxie mit besonderer berücksichtigung der hereditären formen. Virchows Arch. Path. Anat., 70, 140-152.

GREENFIELD, J. G. (1954). The spinocerebellar degenerations. Blackwell Scientific Publications, Oxford.

KARK, R. A. P., BLASS, J. P. and ENGEL, W. K. (1974). Pyruvate oxidation in neuromuscular diseases - Evidence of a genetic defect in two families with the clinical syndrome of Friedreich's ataxia. Neurology, 24, 964-971.

LUBOZYNSKI, M. F. and ROELOFS, R. I. (1975). Friedreich's ataxia: A review of recent literature. South. Med. J., 68(6), 757-763.

SCHUT, J. W. (1950). Hereditary ataxia: Clinical study through 6 generations. Arch. Neurol. and Psychiatry, 63, 535-568.

SCHUT, J. W. (1951). Hereditary ataxia: A survey of certain clinical pathologic and genetic features with linkage data on five additional hereditary factors. Amer. J. Hum. Genet., 3, 93-110.

TYRER, J. H. (1975). Friedreich's Ataxia. Handbook of Clinical Neurology, 21 , 319-364. 